\title{
QUISTE TIROGLOSO GIGANTE. DESCRIPCIÓN DE UN CASO
}

\section{Giant thyroglossal cyst. A case report}

\author{
Juan Miguel PALOMEQUE-VERA ${ }^{1}$; Encarnación FERNÁNDEZ-RUÍZ¹; Emilia LÓPEZ DE HUELVA; María \\ PLATERO SÁNCHEZ-ESCRIBANO ${ }^{3}$; Manuel OLIVA-DOMÍNGUEZ ${ }^{1,2}$ \\ ${ }^{1}$ Hospital Costa del Sol. Servicio de Otorrinolaringología. Marbella. Málaga. ${ }^{2}$ Hospital QuirónSalud Marbella. \\ Servicio de Otorrinolaringología. Marbella. Málaga. ${ }^{3}$ Hospital QuirónSalud Málaga. Servicio de Medicina Interna. \\ Málaga. España.
}

Correspondencia: jm.palomeque@hotmail.com

Fecha de recepción: 24 de marzo de 2018

Fecha de aceptación: 10 de abril de 2018

Fecha de publicación:12 de abril de 2018

Fecha de publicación del fascículo: 1 de septiembre de 2019

Conflicto de intereses: Los autores declaran no tener conflictos de intereses Imágenes: Los autores declaran haber obtenido las imágenes con el permiso de los pacientes Política de derechos y autoarchivo: se permite el autoarchivo de la versión post-print (SHERPA/RoMEO)

Licencia CC BY-NC-ND. Licencia Creative Commons Atribución-NoComercial-SinDerivar 4.0 Internacional Universidad de Salamanca. Su comercialización está sujeta al permiso del editor

RESUMEN: Introducción: los quistes del conducto tirogloso representan entre el 65-70\% de los procesos congénitos del cuello. Se presentan como una masa indolora a nivel cervical anterior en la línea media. Descripción: se presenta el caso de un varón de 52 años con un quiste tirogloso gigante con voz faringolálica y apnea del sueño. Discusión: Solo un 15\% de los casos se diagnostica entre la tercera y la quinta década de la vida. El tratamiento recomendado es la exéresis de la lesión mediante la técnica de Sistrunk. Conclusión: En el caso de quistes tiroglosos de gran tamaño la intubación endotraqueal mediante endoscopia de fibra óptica y con el paciente despierto es aconsejable para tener un buen control de la vía aérea.

PALABRAS CLAVE: quiste tirogloso; tumor cervical; técnica de Sistrunk.

SUMMARY: Introduction: Thyroglossal duct cysts represent between $65-70 \%$ of congenital neck processes. They present as a painless mass at the anterior cervical level in the midline. Description: We present the case of a 52-year-old male with a giant thyroglossal cyst with pharyngolalic voice and sleep 


\section{QUISTE TIROGLOSO GIGANTE. DESCRIPCIÓN DE UN CASO \\ PALOMEQUE-VERA JM}

apnea. Discussion: Only 15\% of cases are diagnosed between the third and the fifth decade of life. The recommended treatment is the exeresis of the lesion using the Sistrunk technique. Conclusion: In the case of large thyroglossal cysts, endotracheal intubation using fiber optic endoscopy and awake patient is advisable to have good control of the airway.

KEYWORDS: thyroglossal duct cyst; cervical tumor; Sistrunk technique.

\section{INTRODUCCIÓN}

Los quistes del conducto tirogloso son defectos congénitos producidos por la persistencia de restos epiteliales embriológicos en el trayecto de la glándula tiroidea. La alteración en la obliteración y reabsorción durante el proceso embrionario dan lugar a estos quistes [1]. Representan entre el $65 \%$ y $70 \%$ de los procesos congénitos que aparecen en el área cervical. Su aparición es rara pasada la quinta década de la vida, estando su incidencia, según los artículos consultados entre el 0.5 al $1 \%$ en la sexta década $[1,2,3,4,5,6,7,8,9]$. Por lo general, se presentan como una masa indolora a nivel cervical anterior en la línea media. En el caso de adquirir un gran tamaño pueden dar síntomas de disfagia, disnea, cambios en la voz o aparición de fístulas a la piel $[3,4]$. El tratamiento debe ser quirúrgico mediante la conocida técnica de Sistrunk en la que debe resecarse el hueso hioides en su parte central con el fin de completar la exéresis del quiste y su conducto hasta el foramen caecum en la base de la lengua [5].

\section{DESCRIPCIÓN}

Varón de 52 años, con antecedentes personales de hipertensión arterial y síndrome de apneahipopnea del sueño (SAHOS) con uso de CPAP. Acudió a consulta por tumoración cervical anterior de crecimiento progresivo desde hacía unos dos años. En la exploración, destacaba voz faringolálica y tumoración cervical palpable sobre hioides y cartílago tiroides, blanda, lisa, bien delimitada y sin pulso, de unos $5 \times 6 \times 3 \mathrm{~cm}$ que se extendía desde área I cervical hacia ambos lados del cuello y se movilizaba con la deglución. En la fibrolaringoscopia, se apreciaba una protrusión de la epiglotis hacia la luz faringolaríngea y un engrosamiento de ambos repliegues aritenoepiglóticos y de aritenoides, sin obstrucción de la orofaringe y con luz glótica permeable con cuerdas vocales móviles (Figura 1). El paciente no refería disfagia. Se solicitó tomografía axial computarizada (TAC) cervical que informaba de imagen trilobulada, de contornos definidos y contenido heterogéneo de $65 \times 55 \times 45$ $\mathrm{mm}$ aproximadamente, que comprimía la laringe y se proyectaba anteriormente entre el hioides y el cartílago tiroides hacia el tejido celular subcutáneo siendo compatible con quiste del conducto tirogloso (Figura 2). Se decidió realizar intervención quirúrgica para exéresis de la lesión mediante cervicotomía siguiendo la técnica de Sistrunk. Durante la intervención, se observó cómo la lesión quística se introducía lateralmente a ambos lados de la laringe hasta ambos senos piriformes (Figura 3). Durante la exéresis del quiste se produjo su rotura, pero finalmente se realizó una completa extirpación (Figura 3). El paciente se recuperó satisfactoriamente con desaparición de la faringolalia y una exploración laríngea normal (Figura 1). En revisiones posteriores, el paciente referido la desaparición del SAHOS.

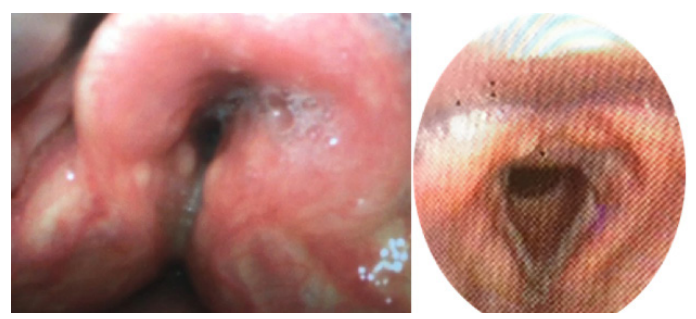

Figura 1. Fibrolaringoscopia durante la intubación (izquierda) y después de la intervención (derecha). 


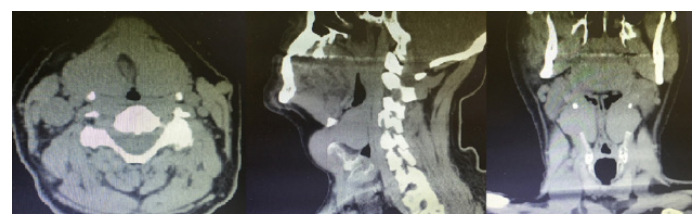

Figura 2. Imágenes de TAC de la tumoración.

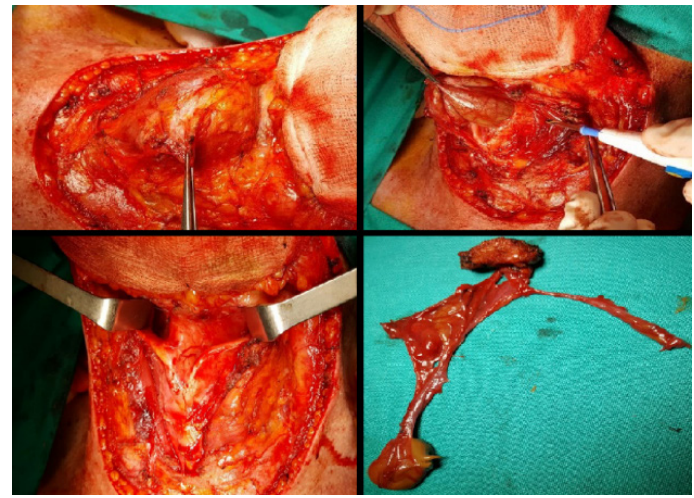

Figura 3: Imágenes durante la intervención.

\section{DISCUSIÓN}

Los quistes del conducto tirogloso se presentan en el $5 \%$ al $7 \%$ de la población, siendo asintomáticos en un porcentaje considerable [1]. Constituyen la anomalía congénita cervical más frecuente. Más del $70 \%$ de los casos se diagnostican durante la infancia, aunque pueden aparecer en cualquier etapa de la vida, alrededor del 15\% de los casos se diagnostica entre la tercera y la quinta década de la vida [2]. En cuanto al sexo, existe un predominio en la mujer con una frecuencia 2:1, sin encontrar causas en la literatura. Estas lesiones suelen oscilar entre $1 \mathrm{~cm}$ y $10 \mathrm{~cm}$ de diámetro, siendo los de mayor tamaño más excepcionales, como es el caso de nuestro paciente. En los quistes de mayor tamaño pueden aparecer síntomas como la disfagia, la disfonía, la voz faringolálica e incluso la existencia de disnea o SAHOS [4]. La complicación más frecuente de esta lesión es la sobreinfección y la fistulización [5].
El diagnóstico es principalmente clínico apareciendo como un tumor redondeado en la base de la lengua que abulta en la región del hueso hioides y que se moviliza durante la deglución [3]. Entre el $1 \%$ al $2 \%$ de los casos estos quistes pueden malignizar, siendo el carcinoma papilar el más frecuente [6]. El diagnóstico diferencial de esta lesión debe realizarse con linfangiomas, quistes dermoides, lipomas, adenopatías inflamatorias, tiroides ectópico o aberrante, nódulos tiroideos o neoplasias entre otros $[1,7]$. Las pruebas de imagen muestran como en un $80 \%$ de los casos estas lesiones aparecen en la porción infrahioidea del cuello. En la ecografía se observa una imagen quística anecoica con pared fina cuando no están infectados y de aspecto homo-heterogéneo según su contenido proteico [8]. En la tomografía axial computarizada, esta tumoración suele mostrar un contenido mucoide, mientras que si existe sobreinfección aparecerá con una densidad similar al músculo [2]. La resonancia magnética nuclear (RMN) muestra imágenes con potenciación siempre alta en T2, mientras que en T1 puede variar de baja a alta, variando según el contenido proteínico del quiste [6]. El tratamiento recomendado del quiste tirogloso es la exéresis de la lesión mediante la técnica de Sistrunk con la escisión de la porción central del hueso hioides con la disección completa del trayecto fistuloso, con esta técnica se consigue la tasa de recurrencia más baja, al realizar una completa exéresis de todo el trayecto fistuloso que atraviesa la porción central de hueso hioides. La tasa de recurrencia de este procedimiento quirúrgico es menor del 5\% [9, 10]. En nuestro caso, la disección se prolongó hacia ambos lados de la laringe en la zona del cartílago tiroides hasta los senos piriformes. Para la intubación endotraqueal del paciente que se comenta en este artículo, dado el grado de obstrucción y protrusión del quiste a nivel laríngeo (Figura 1), fue necesario asegurar la vía aérea con el paciente despierto mediante guía de endoscopia de fibra óptica con catéter de intercambio de ventilación 


\section{QUISTE TIROGLOSO GIGANTE. DESCRIPCIÓN DE UN CASO \\ PALOMEQUE-VERA JM}

como se ha referido en otros centros y con casos similares [11].

\section{CONCLUSIONES}

El quiste tirogloso es la malformación congénita más frecuente en el cuello, aunque aparece con mayor frecuencia en la infancia, puede comenzar a dar síntomas pasada la quinta década de la vida en un porcentaje muy bajo. Aparece como una tumoración cervical anterior que se moviliza con la deglución. En el caso de adquirir un gran tamaño pueden aparecer síntomas como disfagia, disfonía o disnea. El tratamiento de elección es la cirugía mediante la técnica de Sistrunk. En el caso de quistes de gran tamaño o que se extiendan rodeando la laringe hasta la faringe, la intubación endotraqueal mediante endoscopia de fibra óptica y con el paciente despierto es aconsejable para tener un buen control de la vía aérea.

\section{BIBLIOGRAFÍA}

1. Organ $\mathrm{GM}$, Orgam $\mathrm{CH}$. Thyroid gland and surgery of the thyroglossal duct, exercise applied embryology. Word J Surg. 2000; 24:866-90.

2. Ellis PDM, Van Nostrand AWP. The applied anatomy of thyroglosal tract remnants. Laryngoscope.1977; 87:765-70.

3. Ducic Y. Thyroglossal duct cysts in the elderly population. Am Jou Otolaryngol. 2002; 23:17-19.

4. Filho FW, Costa FW, Turatti E, Cavalcante RB. Extensive thyroglossal duct cyst in 83-year-old patient. N Y State Dent J. 2012; 78:39-41.
5. Iwata T, Nakata S, Tsuge H, Koide F, Sugiura M, Otake $\mathrm{H}$, et al. Anatomy-based surgery to remove thyroglossal duct cyst: two anomalous cases. J Laryngol Otol. 2010;124(4):443-6.

6. Cignarelli M, Ambrosi A, Marino A, Lamacchia $\mathrm{O}$, Cincione R, Neri V. Three cases of papillary carcinoma and three of adenoma in thyroglossal duct cysts: clinical-diagnostic comparison with benign thyroglossal duct cysts. J Endocrinol Invest. 2002; 25:947-54.

7. Palomo Luna J; de la Fé Soca AM, Bestard Hartman IC, Ramírez Salinas YM, Suárez Lescay C. Fístula tiroglosa con trayecto infrecuente. Medymay. 2012;16: 185-9.

8. Guzmán P, Baeza A, Cabello A, Montecinos A, Leal $C$, Roa J. Carcinoma papilar en quiste del conducto tirogloso: Reporte de dos casos. Rev Méd Chile. 2008;136:1169-74.

9. Estrada Sarmiento M. Quistes y fístulas del conducto tirogloso: nuestra experiencia. Rev Cubana Cir.1996; 35(2). Disponible en: http://scielo. sld.cu/scielo.php?script=sci_arttext\&pid=S003474931996000200011\&lng=es. [Citado el 10/04/2018]

10. Peretz A, Leiberman E, Kapelushnik J, Hershkovitz E. Thyroglossal duct carcinoma in children: case presentation and review of the literature. Thyroid. 2004; 14:777-85.

11. Gómez-Ríos MÁ, Silva-Carballal I, Freire-Vila E. Use of the TotalTrack VLM for endotracheal intubation in a patient with a giant thyroglossal duct cyst and airway compression. Anaesth Crit Care Pain Med. 2017 Sep 19. pii: S23525568(17)30169-8. 